\title{
Pendampingan Pengelolaan Administrasi Keuangan Paguyuban Selter L PKL Alun-Alun Klaten
}

\author{
Astuti Yuli Setyani \\ Program Studi Akuntansi Fakultas Bisnis \\ Universitas Kristen Duta Wacana, Yogyakarta \\ Email: Astutiys@staff.ukdw.ac.id
}

\begin{abstract}
Abstrak-Paguyuban Selter L PKL Alun-alun Klaten merupakan kelompok pedagang yang berjualan di alun-alun Klaten. anggota paguyuban sebanyak 25 yang terdiri dari pedagang dengan beberapa jenis dagangan yang dijual, namun sebagian besar berdagang makanan. Pedagang berjualan dari pagi sampai malam dan tidak ada batasan waktu karena pedagang Selter $L$ ini mempunyai lapak yang permanen sehingga sudah mempunyai ijin untuk berdagang di lapak tersebut. Paguyuban Selter L melakukan pertemuan setiap sebulan sekali yaitu di Minggu Pertama dan dilakukan pada malam hari. tujuan dari melakukan kegiatan Simpan Pinjam adalah agar anggota Paguyuban tidak meminjam uang atau terjerat oleh rentenir tapi akan meminjam dari tabungan para anggotanya. Namun kegiatan paguyuban ini belum terdokumentasi dengan baik khususnya dalam hal administrasi keuangannya, pencatatan hasil rapat, pengelolaan kas masih belum tertib sehingga perlu adanya pendampingan dan penyuluhan. Dengan permasalahan yang ada tujuan pengabdian yaitu mendampingi, memberikan penyuluhan dan masukan mengenai cara pencatatan, pelaporan dan transparasi dalam menyampaikan laporan keuangan paguyuban. Metode yang digunakan dalam pengabdian ini dengan penyuluhan, pendampingan dan monitoring. Hasil dari pengabdian ini adalah pencatatan dan pendokumentasian laporan keuangan menjadi lebih tertata, tertip dan mudah dipahami serta yang terpenting adanya transparansi laporan kepada semua anggota Paguyubab Selter L PKL Alun-alun Klaten dan simpanan anggota semakin banyak dan berkembang.
\end{abstract}

Keywords : Paguyuban, Simpan, Pinjam, Pencatatan, Keuangan

Abstract-Paguyuban Selter $L$ for street vendors is a group of traders who sell mostly food and beverages at the Klaten Square. There are 25 street vendors who join in this association. The street vendors in Selter $L$ have already got their permanent stalls and the license to trade there so that they can sell their products until late at night. Paguyuban Selter $L$ hold a meeting for the members once a month (every first Sunday) at night. The purpose of this meeting is to carry out Savings and Loans Activities so that the members do not borrow money from the moneylenders instead they can help each other by using the savings of other members. However, the activities of this association have not been well documented, especially in terms of the financial administration, and the recording of the results in the meeting discussion. Besides, the cash management system is not wellmanaged either so that there is still a need to give assistance and counseling. The purpose of this community service is to assist, to provide counseling and to give feedback on how to record, report and be transparent in submitting the financial reports of the saving and loans activities. The methods used in this community service are counseling, mentoring and monitoring. Moreover, the most important thing is the transparency of the reports to all members of Paguyuban Selter $L$ at Klaten Square. Thus, member savings will increase and savings and loan activities will continue to grow.

Keywords : Association, Saving, Loan, Reporting, Finance

\section{PENDAHULUAN}

Paguyuban Selter L PKL Alun-alun Klaten merupakan kelompok pedagang yang berjualan di sekitar alun-alun Klaten. Menurut KBBI, Paguyuban adalah perkumpulan yang bersifat kekeluargaan, didirikan orang-orang yang sepaham (sedarah) untuk membina persatuan (kerukunan) di antara para anggotanya ${ }^{[1]}$. Kelompok ini terdiri dari 25 anggota yang terdiri dari pedagang dengan beberapa jenis dagangan yang dijual, namun sebagian besar berdagang makanan. Dalam penjualannya bisa dilakukan dari pagi sampai malam tidak ada batasan waktu karena pedangan Selter L ini mempunyai lapak yang permanen sehingga sudah mempunyai ijin untuk berdagang di lapak tersebut. Paguyuban Selter L melakukan pertemuan setiap sebulan sekali yaitu di Minggu Pertama dan dilakukan pertemuannya malam hari. Pembentukan Paguyuban Selter L ini baru dimulai 1 Januari 2021 dengan tujuan bisa mengelola kegiatan-kegiatan yang akan dilakukan dapat terkoordinir dengan baik. Paguyuban dapat membina kerukunan dan kekompakan diantara anggota, untuk bertukar pikiran dalam pembangunan dalam satu lingkungan tersebut ${ }^{[2]}$. Selain tujuan dapat terkoordinir dengan baik dengan dibentuknya paguyuban tersebut adalah agar anggota dapat membantu anggota dalam masalah keuangan. Dengan demikian, ketika paguyuban dikelola dengan baik oleh para pengurus yang telah diplih dan 
ditunjuk oleh anggota paguyuban maka tujuan paguyuban untuk meningkatkan kesejahteraan para anggotanya dapat tercapai $^{[3]}$.

Dalam mengatasi keuangan anggota paguyuban dibentuk kegiatan simpan pinjam. Keinginan melakukan kegiatan Simpan Pinjam adalah agar anggota Paguyuban tidak meminjam uang atau terjerat oleh rentenir tetapi akan meminjam dari tabungan para anggotanya. Paguyuban yang dikelola oleh pengurus ini, anggota dapat meminjam dan menabung uang dari paguyuban dan tentunya dengan bunga yang lebih terjangkau oleh anggotanya. Dalam sistem menabung, anggota paguyuban dapat menabung sebesar Rp 3000/perhari. Anggota paguyuban Semboyan paguyuban Selter L Alun-alun Klaten adalah "Dari Kita Untuk Kita". Namun dalam prakteknya, pencatatan simpan pinjam dan aturan-aturannya belum tertata dengan baik dan tertib. Sistem pembukuan dan pencatatan tersebut akan digunakan sebagai bentuk pertanggungjawaban pengurus paguyuban kepada anggota atas pengelolaan keuangan paguyuban ${ }^{[4]}$. Permasalahan lain yang sering dihadapi dalam Paguyuban Selter L adalah setiap diadakanya pertemuan Paguyuban belum ada notulen sehingga keputusan bulan-bulan yang lalu kadang terlupakan. Notulen atau notula menurut KBBI adalah catatan singkat mengenai jalannya persidangan atau rapat serta hal yang dibicarakan dan diputuskan di dalamnya ${ }^{[5]}$. Hal tersebut mengakibatkan adanya pembicaraan ulang dikarenakan tidak ada pendokumentasian dengan baik. Kesadaran mengenai pentingnya pembukuan dan pencatatan dikalangan para pengurus organisasi masing kurang ${ }^{[6]}$. Hal tersebut menyulitkan bagi keberlangsungan pembukuan keuangan paguyuban. Kurangnya kesadaran pentingnya pembukuan dan laporan keuangan tidak terlepas dari faktor individu masing-masing pengurusnya ${ }^{[7]}$.

Dengan permasalah yang ada di atas kami berkeinginan untuk melakukan pendampingan dan pembinaan dalam administrasinya. Kami sudah melakukan pendampingan mulai bulan Maret 2021 dengan mengikuti kegiatan pertemuan yang dilakukan Paguyuban Selter L sehingga kami bisa memetakan permasalahan-permasalahan yang ada di dalam kegiatan paguyuban tersebut. Dalam kegiatan tersebut perlu adanya laporan tentang admistrasi, seperti melaporkan kas yang dimiliki oleh Paguyuban. Karena informasi laporan kas sangat dibutuhkan oleh sebuah organisasi. Seperti peraturan yang mengatur akuntansi dikenal sebagai GAAP, yaitu singkatan dari generally accepted accounting principles atau prinsipprinsipakuntansi berterima umum ${ }^{[8]}$. Selain itu, paguyuban harus menerapkan prisnsip transparansi laporan keuangan paguyuban. Agar menjadi paguyuban yang professional, tidak dapat lagi menggunakan cara-cara yang konvestional (Kesepakatan), apalagi saat ini kita telah masuk pada era keterbukaan informasi, sehingga informasi dalam bentuk apapun harus di akses seluas-luasnya oleh setiap anggota paguyuban. Tujuan utama pelaporan keuangan adalah menyediakan informasi yang bermanfaat untuk membuat keputusan investasi atau memberikan pinjaman ${ }^{[9]}$. Dengan demikian walaupun paguyuban ini masih sangat kecil namun pelaporan dan transparasi keuangan sangat dibutuhkan dan harus dilakukan.

\section{RUMUSAN MASALAH}

Permasalahan yang dihadapi oleh Paguyuban Selter L PKL Alun-alun Klaten yang telah diskusikan antara tim pengabdi dari Fakultas Bisnis UKDW dan mitra di Klaten, dapat dirumuskan sebagai berikut :

1. Setiap kegiatan Pertemuan belum terdokumentasi dengan baik, dalam pelaksanaannya belum ada susunan acara dan notulen.

2. Administrasi keuangan Simpan Pinjam belum dibukukan secara baik, dalam pencatatannya masih kurang memadai.

3. Belum adanya rasa memiliki paguyuban dengan tingkat kesadaran kehadiran dalam pertemuan masih kurang.

4. Kurangnya kepedulian sosial pada lingkungan, misalnya dalam hal gotong royong pembersihan sekitar lingkungan tempat berdagang.

\section{METODE PELAKSANAAN}

A. Metode penyelesaian masalah

Berdasarkan rumusan masalah diatas, prosedur kerja untuk menyelesaikan masalah dapat dilakukan sebagai berikut:

1. Penyuluhan, menumbuhkan motivasi para anggota dilaksanakan bersama antara tim Pengabdi dan Mitra, yang akan dilakukan di Paguyuban Selter L dengan nara sumber dari tim pengabdi, yang bisa memperkuat paguyuban.

2. Melakukan pendampingan dengan selalu menghadiri pertemuan-pertemuan yang diadakan oleh Paguyuban

3. Memberikan masukan-masukan dalam pengelolaan paguyuban misalnya tentang bagaimana dalam pengelolaan administrasi keuangan, Simpan Pinjam, Notulen, Kas Paguyuban dan kas kegiatan sosial.

4. Monitoring dilakukan antara pengabdi, mahasiswa dan para pemangku kepentingan.

B. Teknik Pengumpulan Data

Pengabdi akan melakukan kunjungan lapangan, ikut serta dalam rapat rutin pertemuan, dan melakukan pengamatan pada saat rapat paguyuban selter L Alun-Alun Klaten.

C. Teknik Analisis Data 
Dari hasil pengumpulan data melalui pengamatan dan kunjungan lapangan pada saat rapat rutin pertemuan paguyuban Selter L Alun-Alun Klatem, pengabdi akan melakukan evaluasi. Evaluasi dipergunakan sebagai upaya perbaikan program untuk tahun-tahun mendatang agar lebih maju dalam hal pemahaman administrasi keuangan dan melakukan pencatatan dengan baik dan benar.

D. Lokasi, Waktu, dan Durasi Kegiatan.

Pengabdian sudah dimulai sejak bulan Maret 2021 dengan dan akan sampai bulan Oktober 2021 yaitu dengan waktu 8 bulan pendampingan. Lokasi penelitian ada di Paguyuban Selter L di Alun-Alun Klaten, Kabupaten Klaten.

\section{HASIL DAN PEMBAHASAN}

Paguyuban Selter L PKL Alun-alun Klaten anggota kelompok pedagang yang berjualan di sekitar alun-alun Klaten. Kelompok ini terdiri dari 25 anggota yang terdiri dari pedagang yang berbeda-beda. Pembentukan Paguyuban Selter L ini baru dimulai 1 Januari 2021 dengan tujuan bisa mengelola kegiatan-kegiatan yang akan dilakukan dapat terkoordinir dengan baik. Paguyuban melakukan pertemuan rutin setiap sebulan sekali di minggu pertama awal bulan. Berdasarkan hasil pengamatan dan kunjungan lapangan pada rapat rutin pertemuan Paguyuban Selter L Alun-Alun Klaten, pengabdi melakukan evaluasi dan perbaikan pada sistem kerja di dalam Paguyuban tersebut.

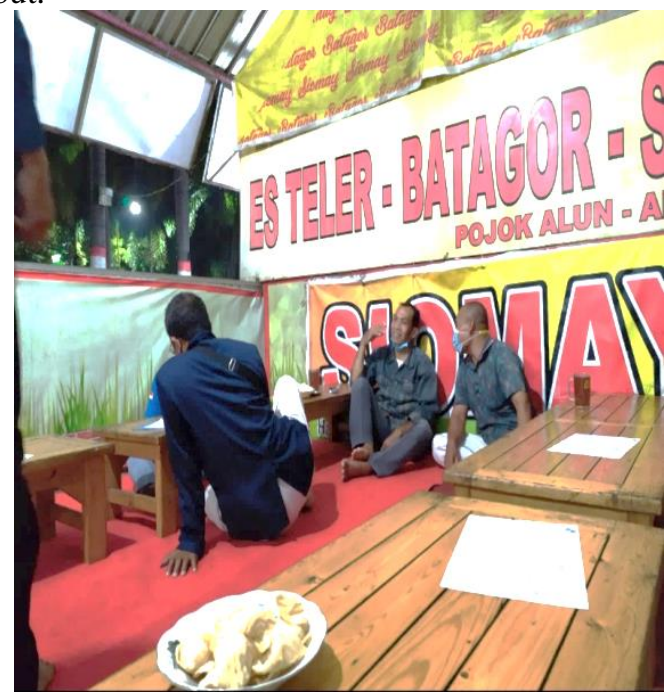

Gambar 1. Rapat Rutin Paguyunan

Adapaun perbaikan yang sudah dijalankan sesuai dengan rencana kegiatan dengan berbagai capaian sesuai dengan luaran yang ditargetkan adalah sebagai berikut:

A. Pencatatan Notulen Rapat
Pencatatan notulen rapat dilakukan setiap paguyuban Selter L Alun-Alun Klaten melakukan rapat rutin. Hasil notulen akan dijadikan dokumen penting dan menjadi bahan rujukan untuk rapat selanjutnya. Selain itu, Notulen rapat sebelumnya bisa dijadikan referensi bagi anggota yang sebelumnya absen. Dengan begitu, anggota yang baru mengikuti rapat sudah mengetahui hasil dari rapat sebelumnya. Beberapa fungsi notulen lainnya, yaitu: (1) Bukti tertulis berlangsung rapat atau sidang, (2) Tolak ukur keberhasilan rapat (apakah tujuan rapat telah dicapai atau belum), (3) Tolak ukur pengambilan tidakan setelah rapat. Namun sebelum membacakan notulen, perlu adanya pembacaan susunan acara. Susunan acara dilakukan agar selama rapat dapat berjalan sesuai rencana dan teratur. Salah seorang anggota perlu membacakan susunan acara rapat rutin Paguyuban sebagai berikut:

\section{SUSUNAN ACARA}

Susunan Acara Rapat Rutin Paguyuban Selter L AlunAlun Klaten:

1. Pembukaan

2. Sambutan Ketua Paguyuban

3. Pembacaan Notulen Rapat

4. Pembacaan Kas

$\checkmark$ Pembacaan Kas Paguyuban

$\checkmark$ Pembacaan Kas Sosial

$\checkmark$ Pembacaan Kas Simpan Pinjam

5. Inti Acara

6. Penutup

Setelah membacakan susunan acara, sekretaris atau anggota yang ditunjuk untuk menulis notulen perlu mencatat setiap hasil rapat ${ }^{[10]}$. Notulen rapat bulan lalu dibacakan ulang di rapat bulan ini, sehingga hasil keputusan atau agenda bulan lalu dapat teringat kembali di rapat bulan ini. Notulen juga mempermudahkan pemimpin rapat untuk membahas masalah atau agenda yang akan diselesaikan pada pertemuan rapat bulan ini. Selama rapat rutin berlangsung, penulis/sekretaris harus mencatat setiap keputusan,agenda, dan semua informasi yang diabahas dalam rapat tersebut. Dengan adanya notulen, setiap kegiatan pertemuan dapat terdokumentasi dengan baik dan teratur. Contoh notulen rapat dapat dilihat dalam gambar 1 Notulen Rapat berikut ini: 


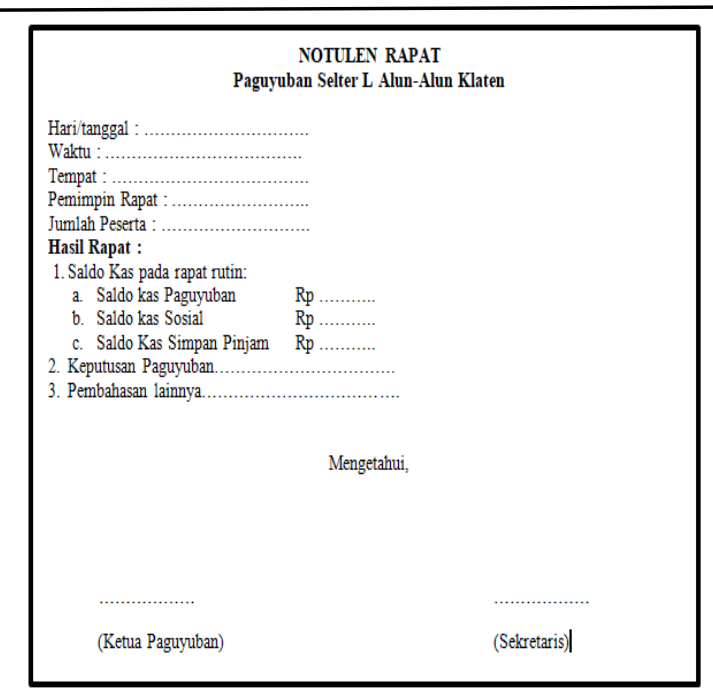

Gambar 1. Notulen Rapat

B. Administrasi keuangan Simpan Pinjam dan Kas Paguyuban

\section{1) Simpan atau Tabungan}

Pengurus perlu membuat Pencatatan simpanan untuk Setiap anggota yang melakukan simpanan/tabungan, sehingga masing-masing anggota memiliki buku simpanan atau buku tabungannya sendiri. Buku tabungan atau Buku Simpanan adalah buku yang berfungsi sebagai pencatatan uang keluar, uang masuk, dan jumlah dana simpanan untuk masing-masing anggota. Di dalam Paguyuban, anggota diwajibkan untuk menyetorkan simpanan awal sebesar Rp 50.000/anggota. Bunga simpanan di paguyuban sebesar 7\%/tahun. Simpanan selanjutnya, anggota dapat membayarkan perhari Rp 3.000. Anggota paguyuban telah menyepakati dalam sebulan ada 30 hari. Jadi apabila simpanan yg diberikan oleh anggota tidak diberikan setiap hari, maka dapat menyetorkan simpanan/tabungan sebulan sekali dengan total Rp 90.000.

Setelah simpanan ini terkumpul dalam 1 bulan, maka uang akan dipinjamkan kembali ke anggota. Hal ini salah satu tujuan paguyuban agar anggota paguyuban tidak meminjam uang ke renternir/bank. Seperti dijelaskan sebelumnya pada bagian pendahuluan bahwa semboyan paguyuban Selter L Alun-Alun Klaten adalah "Dari Kita Untuk Kita" sehingga anggota dapat meminjam uang dari paguyuban dengan bunga yang ringan dibandingkan dengan peminjaman di rentenir/bank konvensional.

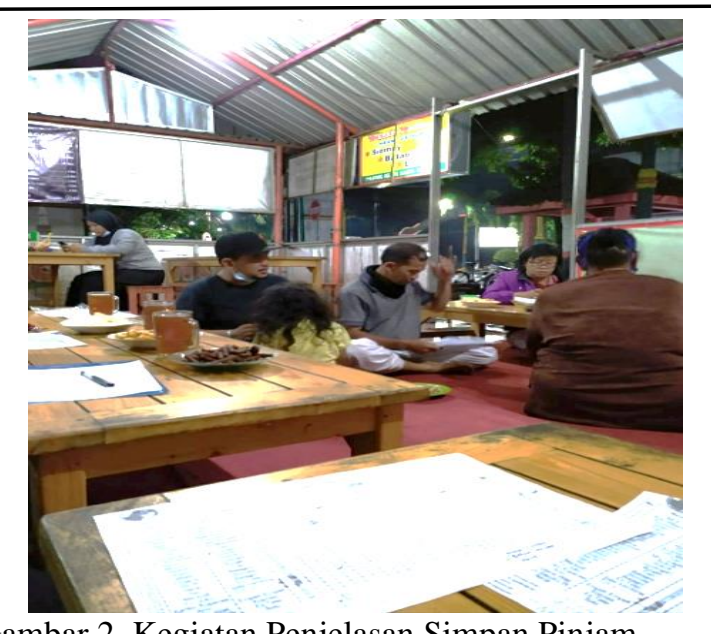

Gambar 2. Kegiatan Penjelasan Simpan Pinjam

Harapanya, jika simpanan semakin banyak dan jumlah simpanan perhari besar maka paguyuban dapat meminjamkan kembali ke anggota lainnya. Jadi bisa membantu kebutuhan pada anggota lainnya, kebutuhan membayar sekolah atau dapat membantu anggota memperbesar modal usaha. Pencatatan Simpan dibuat peranggota yang melakukan simpanan. Pencatatan simpanan dilakukan oleh petugas khusus simpan pinjam yang sudah disepakati oleh para anggota paguyuban. Pencatatan dilakukan pada hari yang sama pada saat anggota melakukan simpanan, sehingga data dalam buku dapat tercatat urut sesuai tanggal. Berikut Contoh tabel pencatatan simpanan/tabungan yang dapat dilihat dalam tabel 1 Pencatatan Simpanan berikut ini.

Tabel 1. Pencatatan Simpanan

\begin{tabular}{|c|c|c|c|c|}
\hline \multicolumn{4}{|c|}{ NAMA ANGGOTA $: \ldots \ldots \ldots \ldots \ldots \ldots \ldots$} \\
\cline { 3 - 4 } No & \multirow{2}{*}{ Tanggal } & $\begin{array}{c}\text { Debet } \\
(\mathrm{Rp})\end{array}$ & $\begin{array}{c}\text { Kredit } \\
(\mathrm{Rp})\end{array}$ & $\begin{array}{c}\text { Saldo } \\
(\mathrm{Rp})\end{array}$ \\
\hline 1 & & & & \\
\hline 2 & & & & \\
\hline 3 & & & & \\
\hline 4 & & & & \\
\hline dst & & & & \\
\hline
\end{tabular}

2) Pinjam / Hutang

pinjam adalah tagihan paguyuban atas anggota paguyuban berupa pinjaman dalam bentuk tunai. Pinjaman di paguyuban, tidak menggunakan agunan tetapi berdasarkan asas kepercayaan. Bunga yang ditetapkan di paguyuban adalah sebesat $10 \%$. Jangka waktu pinjaman adalah 5 bulan saja. Apabila dalam waktu 5 bulan tersebut anggota peminjam tidak bisa melunasi maka pinjaman harus diperbaharui. Pembaharuan didasarkan atas sisa pinjaman kemudian dikenakan bunga $10 \%$ lagi dan akan diberi waktu 5 bulan lagi untuk melunasi. Oleh karena itu, dalam pembaharuan tersebut dikenai bunga baru dan masa jangka waktu 5 bulan lagi. Namun saat pembaharuan, 
peminjam tidak diperbolehkan untuk menambah pinjaman. Apabila peminjam ingin menambah pinjaman, maka perlu melunasi hutang/pinjaman sebelumnya terlebih dahulu. Hal tersebut diharapkan agar anggota cepat melunasi pinjamannya dan bisa dipinjamkan ke anggota lainnya. Salah satu tujuannya agar pinjaman merata seluruh anggota.

Pencatatan Pinjam dibuat peranggota yang melakukan pinjaman, contoh tabel dapat dilihat dalam tabel 2 Pencacatan Pinjaman berikut ini.

Tabel 2 Pencatatan Pinjaman

\begin{tabular}{|c|c|c|c|c|}
\hline \multicolumn{3}{|c|}{$\begin{array}{l}\text { Nama Peminjam } \\
\text { Plafon } \\
\text { Tenor } \\
\text { Bunga }\end{array}$} & \multicolumn{2}{|c|}{$\begin{array}{l}\ldots \ldots \ldots \ldots \\
\operatorname{Rp} \ldots \ldots \ldots \ldots \ldots \ldots \\
\ldots \ldots \ldots \ldots \ldots \ldots \ldots \ldots \ldots\end{array}$} \\
\hline \multirow[b]{2}{*}{$\begin{array}{c}\text { Bulan } \\
\text { Ke- }\end{array}$} & \multicolumn{2}{|c|}{ Angsuran } & \multirow[b]{2}{*}{$\begin{array}{c}\text { Jumlah } \\
\text { Bayar }\end{array}$} & \multirow{2}{*}{$\begin{array}{c}\text { Saldo } \\
\text { Pinjaman }\end{array}$} \\
\hline & $\begin{array}{c}\text { Pokok } \\
\text { (Rp) }\end{array}$ & $\begin{array}{c}\text { Bunga } \\
\text { (Rp) }\end{array}$ & & \\
\hline 0 & & & & \\
\hline 1 & & & & \\
\hline 2 & & & & \\
\hline 3 & & & & \\
\hline 4 & & & & \\
\hline 5 & & & & \\
\hline dst & & & & \\
\hline
\end{tabular}

Saat ini, paguyuban hanya mampu meminjamkan sebesar Rp 500.000 - Rp 1.000.000/anggota. Pencatatan simpan / pinjam dilakukan oleh petugas khusus simpan pnjam yang sudah ditetapkan paguyuban, sehingga tidak semua kegiatan keuangan dipegang oeh bendahara. Pencatatan ini diharapkan mampu membantu pengurus dalam mengelola keuangan simpan pinjam di Paguyuban.

3) Pencatatan Kas Sosial Paguyuban

Pencatatan kas paguyuban dilakukan untuk mencatat penerimaan dan pengeluaran uang oleh Bendahara. Pencatatan transaksi dimulai dengan mengidentifikasi bukti-bukti pengeluaran ataupun penerimaan, kemudian dicatat dalam laporan secara kronologis/urut sesuai tanggal dalam satu buku. Pencatatan kas paguyuban hanya mencatat pemasukan uang sosial sebesar Rp 10.000/bulan dan dapat dicatat perbulan untuk semua anggota. Sedangkan kas keluar meliputi pengeluaran kas untuk keperluan paguyuban seperti kegiatan sosial tali asih kepada anggota yang sakit sebesar Rp 200.000, pengeluaran untuk gotong royong, dan kegiatan social lainnya. Contoh tabel pencatatan kas sosial peranggota dapat dilihat dalam tabel 3 Pencacatan Kas Sosial. Pencatatan penerimaan kas kegiatan sosial dilaksanakan setiap sebulan sekali dengan menjumlah pembayaran kas sosial dari semua anggota selama sebulan. sehingga anggota perlu membayar iuran sosial setiap sebulan sekali. Contoh
Tabel kas penerimaan dan pengeluaran dapat dilihat pada tabel 4 Pencatatan Penerimaan dan Pengeluaran Kas Sosial.

Tabel 3. Pencatatan Kas Sosial per-Anggota

\begin{tabular}{|c|c|c|c|c|c|c|c|}
\hline \multirow[b]{2}{*}{ No } & \multirow[b]{2}{*}{ Nama } & \multicolumn{6}{|c|}{ Bulan } \\
\hline & & Jan & Feb & Mar & $\begin{array}{c}\text { Apr } \\
1\end{array}$ & $\begin{array}{c}\mathrm{Me} \\
\mathrm{i}\end{array}$ & Dst. \\
\hline 1 & & & & & & & \\
\hline 2 & & & & & & & \\
\hline 3 & & & & & & & \\
\hline 4 & & & & & & & \\
\hline 5 & & & & & & & \\
\hline $\mathrm{dst}$ & & & & & & & \\
\hline
\end{tabular}

Tabel 4. Pencatatan Penerimaan dan Pengeluaran Kas Sosial

\begin{tabular}{|l|l|l|l|l|}
\hline Tgl & Uraian & $\begin{array}{c}\text { Penerimaan } \\
(\mathrm{Rp})\end{array}$ & $\begin{array}{c}\text { Pengeluaran } \\
(\mathrm{Rp})\end{array}$ & $\begin{array}{c}\text { Saldo } \\
(\mathrm{Rp})\end{array}$ \\
\hline & & & & \\
\hline & & & & \\
\hline & & & & \\
\hline & & & & \\
\hline & & & & \\
\hline & & & & \\
\hline & & & & \\
\hline & & & & \\
\hline
\end{tabular}

4) Menumbuhkan Semangat Gotong Royong dan Kepedulian Sosial

Kurangnya kepedulian sosial pada lingkungan, misalnya dalam hal gotong royong pembersihan sekitar lingkungan tempat berdagang, maka setiap sekali perlu diadakan kerja bakti di lingkungan Selter L Alun-Alun klaten agar tetap bersih. Jika tempat berdagang bersih, maka menarik minat pembeli/konsumen. Sebaliknya, jika tempat berdagang kotor maka pembeli/konsumen enggan untuk membeli. Untuk itu, perlu adanya sikap saling mendukung dan bekerja sama dalam mewujudkan tempat berdagang yang bersih dan nyaman. Para anggota perlu menyamakan tujuan tersebut agar kekompakan antar anggota terjaga. 


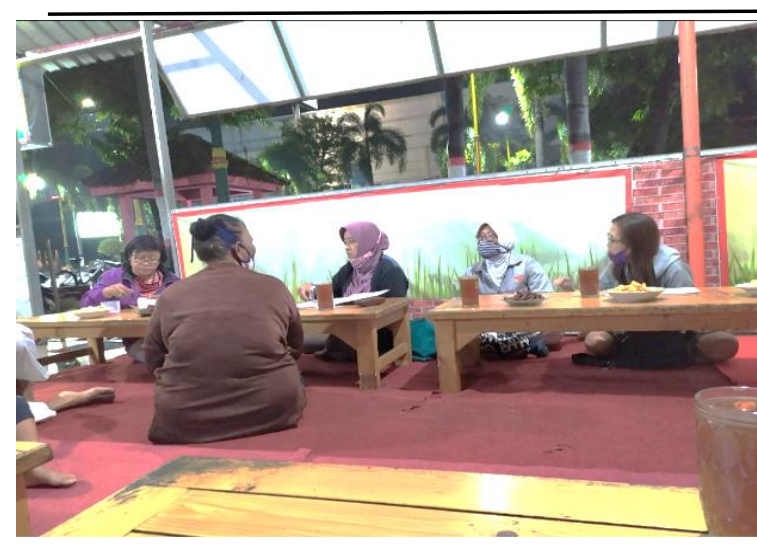

Gambar 3. Kegiatan Pelatihan Pembukuan

Selain itu, belum adanya rasa memiliki paguyuban dengan tingkat kesadaran kehadiran dalam pertemuan masih kurang. Diharapkan setiap pertemuan diberi undangan peranggota untuk menghadiri rapat rutin, sehingga jika terdapat pengumuman dari Disperindag (Dinas Perindustrian dan Perdagangan) anggota menegtahui informasi dari dinas tersebut. Tidak jarang Dinas juga memberikan pengarahan dan pendampingan di paguyuban.

\section{KESIMPULAN DAN SARAN}

\section{A. Kesimpulan}

Paguyuban Selter L PKL Alun-alun Klaten merupakan kelompok pedagang yang berjualan di sekitar alun-alun Klaten. Pembentukan Paguyuban Selter L ini baru dimulai 1 Januari 2021 dengan tujuan bisa mengelola kegiatankegiatan yang akan dilakukan dapat terkoordinir dengan baik. Selain tujuan dapat terkoordinir dengan baik dengan dibentuknya paguyuban tersebut adalah agar anggota dapat membantu anggota dalam masalah keuangan. Dalam mengatasi keuangan anggota paguyuban dibentuk kegiatan simpan pinjam. Namun dalam prakteknya, pencatatan simpan pinjam dan aturan-aturannya belum tertata dengan baik dan tertib. Permasalahan lain yang sering dihadapi dalam Paguyuban Selter L adalah setiap diadakanya pertemuan Paguyuban belum ada notulen sehingga keputusan bulan-bulan yang lalu kadang terlupakan.

Dengan permasalah tersebut pengabdi melakukan pendampingan dan pembinaan dalam administrasi pencatatannya. Kami sudah melakukan pendampingan mulai bulan Maret 2021 dengan mengikuti kegiatan pertemuan yang dilakukan Paguyuban Selter L sehingga kami bisa memetakan permasalahan-permasalahan yang ada di dalam kegiatan paguyuban tersebut. Dengan demikian walaupun paguyuban ini masih sangat kecil namun pelaporan dan transparasi keuangan sangat dibutuhkan dan harus dilakukan.

Berdasarkan hasil pengamatan dan kunjungan lapangan pada rapat rutin pertemuan Paguyuban Selter L Alun-Alun
Klaten, pengabdi melakukan evaluasi dan perbaikan pada sistem kerja di dalam Paguyuban tersebut. Adapaun perbaikan yang sudah dijalankan sesuai dengan rencana kegiatan dengan berbagai capaian sesuai dengan luaran yang ditargetkan yaitu (1) Paguyuban mempunyai dokumentasi atas kegiatan yang dilakukan oleh Paguyuban Selter L dalam bentuk Notulen dan Susunan Acara. (2) Administrasi Paguyuban tersusun dan tertata dengan baik dan benar, tercermin dari telah disepakati aturan-aturan dalam simpan pinjam dan kas social. (3) Mempunyai rasa memiliki Paguyuban dan menumbuhkan sikap kegotongroyongan, tercermin dari adanya undangan setiap rapat dan gotong royong membersihkan lingkungan Selter L Alun-Alun Klaten.

Dengan adanya dokumentasi yang telah disepakati oleh semua anggota, maka pengurus dapat melaporkannya dengan tertib dan rapi. Dan diharapkan dengan adanya pendampingan yang akan dilakukan selama 8 bulan ini peguyuban Selter L bisa lebih maju dan admisitrasi keuangannya akan tercatat dan tertata lebih baik dan benar.

\section{B. Saran}

Pengabdi berharap Paguyuban Selter L Alun-Alun Klaten tetap melakukan pencatatan yang telah diajarkan oleh pengabdi agar setiap laporan administasi keuangan dan administrasi lainnya dapat berjalan dengan aman dan tertib. Transparasi laporan keuangan juga sangat diperlukan bagi paguyuban untuk itu, perlu adanya pembacaan notulen setiap kas simpan/pinjam atau pun kas sosial paguyuban. Dengan adanya paguyuban Selter L Alun-Alun Klaten, diharapkan bertambahnya anggota yang mengikuti kegiatan di paguyuban dan simpanan semakin banyak sehingga uang yang akan dipinjamkan juga semakin banyak.

\section{Ucapan Terima Kasih}

Kami mengucapkan terima kasih kepada LPPM yang telah mengakomodasi kami melakukan pengabdian masyarakat dalam Pendampingan Pengelolaan Administrasi Keuangan Paguyuban Selter L PKL Alun-alun Klaten.

\section{DAFTAR PUSTAKA}

[1] Pengertian Paguyuban. KBBI [online], available: https://kbbi.web.id/paguyuban. (Accessed 1 Mei 2021)

[2] Purnomo Agus Sidiq. "Sistem Pembukuan Kas Untuk Transparansi Keuangan (Studi Kasus: Paguyuban Bangun Desa, Krandon RT 003 RW 043 Malangan)" dalam Seminar Nasional Multimedia dan Artificial Intellegence (SMAI), Yogyakarta, Indonesia, 2020.

[3] Handajani, Lilik, Budi Santoso dan Ahmad Rifa'i. "Permasalahan Manajerial Dan Keuangan Pada Koperasi Yang Mengalami Kendala Dalam Penyelenggaraan Rapat Anggota Tahunan”. Jurnal Abdi Insani LPPM Unram, volume 6, nomor 1, 2019. 
[4] Setiawan, Achma Hendra. "Sistem Pembukuan dalam Administrasi Koperasi" dalam Jurnal Dinamika Pembangunan Vol. 2 no 1 hal. 57-65, 2005.

[5] Serba Serbi Notulen dalam web https://www.kompas .tv, serba serbi notulen: pengertian, fungsi, tujuan. 29 mei 2021

[6] Solikah, Mar'atus; Puji Astuti dan Dyah Ayu Paramitha. 2017. Analisis Faktor-Faktor yang Mempengaruhi Persepsi Wirausahawan Terhadap Pentingnya Pembukuan dan Laporan Keuangan. Jurnal Akuntansi \& Ekonmi FE. UN PGRI Kediri Vol. 2 No. 2 (12-21)

[7] Astuti, Ismadiyanti Puwaning. "PENCATATAN KEUANGAN BERBASIS DIGITAL PADA
PAGUYUBAN PENGRAJIN SANGKAR BURUNG "KARYA MANDIRI"” dalam Seminar Hasil Pengabdian Masyarakat 2019, Universitas Amikom Yogyakarta, 2019.

[8] Charles T. HoFrngren dan Walter T. Harrison.2007. Akuntansi Jilid Satu Edisi Tujuh. Penerbit Erlangga: Jakarta

[9] Kieso , Intermediate Accounting IFRS Edition, John Wiley \& Son.2014

[10]pengertian notulen. Dalam website https:// dosenpendidikan.co.id 12 September 2021 